\title{
Study on the Negative Effects and Countermeasures of Internet on Ideological and Political Education
}

\author{
Guanghua Wang \\ Weifang University of Science and Technology, ShanDong ShouGuang, 262700,China.
}

Keywords: Network; College students; Negative influence; Research Countermeasures

\begin{abstract}
The main purpose of the article is to study on the negative influence caused by network on ideological and political education of College students. Through the questionnaire survey method to analyze the current situation of the use of the network of college students and the negative effect of the presence. A study on the negative effects brought by the network. According to the research results, analysis of the three aspects of government, the University and social, draw the ideas and suggestions for the ideological and political education of college students. Finally is the summary of this study.
\end{abstract}

\section{Introduction}

In order to fully understand and grasp the negative influence of Internet on Ideological and political education of college students and its countermeasures, and earnestly do a good job of the ideological and political education of college students, and comprehensively promote the implementation of the strategy of reinvigorating China through human resource development. Strengthen and enhance the ideological and political education of college students, improve their ideological and political quality. To train them to be the builders and successors of the socialist cause with Chinese characteristics, for the full implementation of the strategy of developing the country through science and education and talent, to ensure that China in the fierce international competition remains invincible. To ensure the ambitious goal of building the well-off society and promoting the socialist modernization comprehensively and comprehensively. To ensure the Chinese characteristics of the prosperity of the cause of socialism, have qualified successors, have significant and far-reaching strategic significance.

\section{Analysis of college students using network status qua}

According to the July 2008 "China Internet development statistics report shows: as of the end of June 2008, the number of Internet users in China reached 253 million, and will continue to show a continued trend of rapid development, the scale of Internet users has leapt to first in the world, of which the main users is still 30 years old and younger age groups, the groups of Internet users account for $68.6 \%$ of Internet users in China, more than two-thirds of the total number of Internet users. Internet users, young college students have become the main group of Internet users in China.

Questionnaire survey data show (as shown in Table 1)

\begin{tabular}{|l|l|l|}
\hline Item & Girl & Boy \\
\hline Often surf the net & $54 \%$ & $58 \%$ \\
\hline Occasional Internet access & $30 \%$ & $21 \%$ \\
\hline Seldom net & $16 \%$ & $11 \%$ \\
\hline Never Internet access & $0 \%$ & $0 \%$ \\
\hline
\end{tabular}

Table 1 Questionnaire survey results

Random interview conclusion. None of the students who were asked had never been on the net, and the popularity of the Internet in college campuses was high. When asked why often, the majority of students said: in the university is very boring, lack of target positioning, lack of interest in the activity. A few students said: in the school rarely find true friendship and love, a rare understanding of their 
classmates and friends, after graduation, employment pressure. Individual students said: look for the harsh reality of the world or unwilling to express the subject. When asked whether because of the Internet and escaped the class, most have said had truancy records, and called on the Internet than lectures interesting. Which also found that freshmen have a lot of students like to go to the phenomenon of groups of people go to the Internet, the reason: competitive games on the Internet for people more Internet cafes to play interesting. Visit also found that the parents of the students in addition to the monthly meeting living expenses outside almost paid little attention to the adult children's thoughts and life issues, and schools are not dedicated to the teacher to be responsible for students' mental health status. As part of the student said: do not make a big mistake not fail the teacher is not trouble you, even want to also be beyond one's grasp of parents.

\section{Negative impact of the network}

The negative effect of Internet Addiction. The super real and the unreal of the network environment, can easily lead to the rebellious behavior of College Students' anti reality.. Network constructs a surreal "Xanadu", there is no learning and survival pressure, there is no real world rules and constraints. The vast expanse of the cyberspace and unrestrained internet life, colorful network game, so that exposure to one of the students release the academic pressure, forget the real life troubles to meet the psychological needs, also make it gradually deviated from the orbit of the real life, infinite dependent on the network are generated, even infected with Internet addiction disorder, which seriously damaged the social and psychological functions of the individual. $5 \%$ to $10 \%$ of Internet users suffer from Internet addiction disorder. Most of them are young people of 20 to 30 years old, and their average weekly time of using the network averaged 38.5 hours. These people surfing in the virtual world are full of wit, in high spirit. Once exiting the network, learning pressure in real life, the troubles of life and emotional confusion and often make it at a loss, malaise. In order to get away from reality, they often indulge in the network and at the neglect of their studies. When the network language, network thinking, network life instead of the living reality of the world, the loss of life goals and direction, the unloading of shared responsibility will become inevitable. Wake indulge in the virtual world "geek", guide them to return to the reality, correct attitude to life, re establishing the scientific world outlook, outlook on life and values, which become the ideological and political theory course teacher's bounden obligation.

The main impact of the bad website. Network information complex and confusing and the mainstream ideology of some university students. There are some websites such as yellow, violence and other content on the Internet, and some reactionary political websites. Mr. Li Chun Qiu said: "the university stage is the young students' Outlook on life, world outlook and values important exercise stage, at this stage to accept the ideas may affect the student's life." Plus, the college students are active in thinking, less restriction, of different culture and value concept of strong inclusive, of information selection and filtration ability is poor, discriminating ability is not strong, easily by the influence of bad information, lead to the fragmentation of the mainstream ideology.

Over reliance on the network, the serious impact of the young students in school and physical health. According to the observation, the fans are reluctant to communicate with the students of the students, and sometimes even show the students and teachers impatient. And the relationship between students indifference, rarely participate in group activities, does not love sports, like a loner, empty bubble on the Internet, immersed in the unreal network world is unable to extricate themselves, thoroughly do captive network. Not only wasted a great achievement, because cannot resist the temptation, some even commit no return. In physiology, college students are in the prime of youth, is the golden age of one's body. If a long time with the computer, not only the eye overload operation, damage vision; also makes the spine deformation, the health of the body is also threatened. 


\section{The ideas and suggestions of the ideological and political education for college students under the negative influence of the network.}

In the network information brings negative effect is becoming more and more serious, though some specific and feasible practices have been taken; colleges and universities have in the innovation of Ideological and political education of college teaching management; and even the society as a whole also focused on College Students' mental health state government. But how to carry out the ideological and political education in universities is still a problem to be solved urgently.

From the angle of improving the government function, the following suggestions are submitted. 1) Strengthen the construction of the Internet, improve the relevant network security laws and regulations

Strengthen the Internet and from a number of comprehensive websites and characteristic websites that have a strong influence both in China and abroad, build a group of networking cultural brand with Chinese style and embody the spirit of the times. First, we should guide the development of network culture, implementation of network content construction projects, and promote the outstanding traditional cultural treasures and contemporary cultural boutique network dissemination. Secondly, supervise and urge the network operation service enterprises to fulfill their legal obligations and social responsibilities, strengthen the guidance and management of social networks and instant communication tools, etc., and regulate the order of the online information dissemination.

2) Increase the security of network information supervision

The existence of false information, spam, pornographic information and ideological infiltration information should be taken in the network to track, monitor, screen and delete the ideological information.. Establish an effective procedure for screening, screening, initiating investigation and filing.

3) Improve the security mechanism of the ideological and political education for College Students

Improve the safety mechanism of College Students' Ideological and political education. To establish a sound system of Ideological and political education and management which is compatible with the laws and regulations, and the overall development of higher education, and the growth of college students needs to adapt to the ideological and political education. To increase the input of funds of the college students' Ideological and political education, the educational administrative departments and schools to reasonably determine the work of Ideological and political education funds investment subjects, included in the budget, to ensure the smooth development of the work.

Starting from the university itself, we can carry out the work from three aspects. 1) Strengthen leadership, implement the performance appraisal system

The university should further establish and improve the students' Ideological and partisan staff of the management and assessment system, strengthen the ideological and political staff of the daily management, strict assessment. The results of the assessment should be related to the appointment, rewards and punishment, promotion and promotion. To the students' Ideological and political teachers to do a detailed ideological and political work to create a working condition and environment. Ensure that they have enough energy to keep the students' Ideological and political work.

2) The combination of educational management and the realization of the institutionalization of campus network morality

Ideological education must be combined with appropriate management measures to receive good results. Colleges and universities should laws and general moral advocate outside, to formulate a more specific moral standards to regulate and constraints of college students network behavior, the organic combination of ethics to admonish and institutional constraints on students, to enable students to develop good habits of network behavior.

3) Improve the personal qualities of the network ideological educators, and strengthen the construction of the professional teachers 
There are certain problems in the ideological and political education in Colleges and universities. Teachers mostly use the lecture notes and achievements to measure the students"s performance and lack the practical investigation and investigation.. Ideological and political work of colleges and Universities under the new situation, ideological and political workers should not be "blind", not only to learning network knowledge, understanding of the network, the use of network, but also to learn to moral education and network technology together. Take the initiative to study the existing social morality which is adapt to the concept of social network, to inherit and carry forward the traditional virtues of the Chinese nation based on the reference of the west is the value of the moral and ethical values, carries on the summary, in order to better application in work.

The ideological and political education of college students needs the participation of the whole society. 1) Parents should be involved in the education management as a supervisor.

Through the investigation, we found that a lot of College Students' parents just students' money machine, monthly charge is the. The most is to ask the money to the account is not enough and the like, if there are extra words is told to study the child to study hard and take care of the end of the call. Not the parents do not want to care about, but because our parents to be beyond one's grasp. Therefore, the university needs to establish the effective communication mechanism with the students' parents, so that parents can also participate in the ideological and political education of the students..

2) To rectify the environment around the campus

Social environment should be made in teaching environment, which requires not only need the efforts of the whole society construction, need more culture, public security, industry and commerce administrative departments at all levels, it is necessary to carry out their duties, strengthen governance, but also complement each other, strengthen cooperation and in-depth development of the surrounding environment of school governance. the university campus for cultural entertainment business subject to strict examination and approval, strict management, strict market access.

3) Create a good social environment

Make full use of newspapers, television, radio and other news media, publicize energetically strengthen the necessity and importance of College Students' Ideological and political education, raise all the people to participate in the enthusiasm of College Students' Ideological and political work carried out under the negative effects of the Internet. Multi pronged, the formation of a joint force, the ideological and political education of college students will certainly do better.

\section{Conclusions}

The ideological and political education of the contemporary college students must face the impact of the network, especially the negative information of the network. This is certainly a new challenge to the traditional ideological and political education, but also there are opportunities. In view of the negative influence of the network, how to better the ideological and political education of college students. This paper puts forward a solution from the viewpoint of the three parts of the country, the University and the society.The three form a organic unity, the formation of an ideological and political education of comprehensive system to comprehensively fundamentally the problems existing in the process of Ideological and political education timely eliminate and solve, to college students' Ideological and political education work to keep pace with the times to promote, in order to have help college students ideological and political ideas real internalization.

\section{References}

[1] The State Council. Opinions on Further Strengthening and improving the ideological and political education for college students [J].2007,3. 
[2] Twenty-sixth times China Internet development status statistics report [R]. (CNNIC), 2010 (7): [3] Shufeng Quan. The problem and analysis of College Students' mental health and analysis of [J]. university education science, 2003, (4).

[4] Weifang Min. Further strengthening and improving ideological and political education [J].2005,3.

[5] Zhongbao Xie. The influence of the Internet on the development of young children [J]. contemporary youth research, 2002,6.

[6] Chunqiu Li. New ethics tutorial [M]. Beijing: Higher Education Press.2002,7.

[7] Custer Manuel. The rise of the network society [M]. Beijing: Social Science Literature Press, 2001.

[8] Jintao Hu. To strengthen and improve the ideological and political education work [J]. banyuetan, 2005,1 .

[9] Guanghai Xie. Internet and ideological and political work of [M]. Shanghai: Fudan University press.2001,7.

[10] Longhui Liao. Analysis of the impact of the network on the socialization of youth [J]. Science economic society, 2001.3. 